\title{
Chemotherapy induces genomic instability in oral mucosal cells of women with breast cancer
}

\author{
Patricia G. Coelho ${ }^{1}$, Sarah R. Marsicano ${ }^{1}$, Pamela O. Delgado ${ }^{1}$, Jorge. L. F. Pinto ${ }^{1}$, Aleksandra V. L. Sant'Anna ${ }^{1}$, \\ Auro Del Giglio ${ }^{1}$, Fernando L. A Fonseca ${ }^{1,2}$ \\ 1. Discipline of Hematology/Oncology, Faculty of Medicine of ABC, Santo André, Brazil. 2. Department of Biological \\ Sciences, Federal University of São Paulo, Diadema, Brazil \\ Correspondence: Fernando Luiz Affonso Fonseca. Address: Discipline of Hematology/Oncology, Faculty of Medicine of ABC, \\ Santo André, Brazil. Telephone: 55-114-993-5488. Fax: 55-114-993-5488. E-mail: Fon_Fonseca@yahoo.com.br
}

Received: September 26, 2011 Accepted: December 28, 2011

Published: April 1, 2012

DOI : $10.5430 /$ jst.v2n2p10

URL: http://dx.doi.org/10.5430/jst.v2n2p10

\section{Abstract}

Objectives: The study of the involvement of non-neoplastic cells with genomic instability has not been sufficiently investigated. Genomic instability induced by treatment chemotherapy with alkylating agents' employment has been reported in different biological matrices like PBMN, and fpDNA fuDNA. We investigated the possible use of DNA from oral mucosal cells to observe the presence of genomic instability being a simple protocol, applicable and non - invasive.

Methods: Genomic instability was determined in oral mucosal cells of 31 women diagnosed with breast cancer before and after chemotherapy with alkylating agents' presence. MSI was assessed by a panel with five different microsatellite regions.

Results: We observed that $77.41 \%$ of patients had any genetic alteration in the oral mucosal cells, with a higher number of MSI events by $32.58 \%$ compared to LOH events by $24.97 \%$, mainly in the FMR2 (16.29\%) and BAT 26 (13.04\%). The control group did not show genomic instability in oral mucosal cells.

Conclusions: The oral mucosal cells are susceptible to genomic instability when exposed to chemotherapy regimens containing alkylating agents which allows us a new approach to chemotherapy regimens and their implications and propose a new biological matrix for assessing such adverse effects.

\section{Key words}

Genomic instability, Breast cancer, Oral mucosal cells, Chemotherapy

\section{I ntroduction}

Systemic treatment represented by chemotherapy is an important part of the approach of patients with breast cancer ${ }^{[1]}$. Despite the consistent improvement in survival of patients the use of alkylating agents during chemotherapy treatment can cause the increase of genomic instability which may be associated with the development of secondary malignancies considered as a late side effect of therapy ${ }^{[1-3]}$.

MSI is defined as a change in size of microsatellite caused by deletion or insertion of nucleotides in the DNA of the tumor when compared with normal tissue ${ }^{[4]}$. Genetic alterations such as loss of heterozygosity (LOH) and microsatellite 
instability (MSI) have been reported in several types of tumors and associated with the inactivation of tumor suppressor genes and mutations in mismatch repair genes and DNA matching errors ${ }^{[5-7]}$.

However, the study of the involvement of non-neoplastic cells with genomic instability and its implication and use as diagnostic and prognostic factor has not been sufficiently investigated. This genomic instability in normal cells may be a potentially important problem, particularly when these cells are used as reference in $\mathrm{LOH}$ and analysis of tumor samples $\mathrm{MSI}^{[8]}$.

Previous work in our study group demonstrated induction of MSI in normal cells of the mononuclear fraction of peripheral blood DNA from urine sediment and plasma DNA of women with breast cancer undergoing chemotherapy regimen with the presence of alkylating agents ${ }^{[2,9]}$. In an in vitro model with lymphocytes exposed to alkylating agents, Marsicano and Pinto et al. showed the presence of genomic instability and decrease of repair protein expression $\mathrm{hMSH} 2{ }^{[9,10]}$.

Thus, this study aimed at the possible use of DNA from oral mucosal cells for observation of the presence of genomic instability observed during chemotherapy in women with treatment breast cancer through a simple protocol, applied, approach and non-invasive approach ${ }^{[11,12]}$.

\section{Methods}

We evaluated women diagnosed with breast cancer without prior treatment for breast cancer, treated in outpatient Oncology, Faculty of Medicine of ABC (FMABC). The control group was composed of 10 volunteer women free of disease in randomly selected FMABC. The project was approved by the Ethics in Research FMABC and all patients and volunteers who agreed to participate signed a consent form. Patients eligible for the study and had their donor samples collected at diagnosis, three and six months after chemotherapy with alkylating agents presence, proposed by the oncologist. Of the 31 patients eligible for the study, 17 agreed to answer a questionnaire about smoking.

Samples of oral mucosal cells from of patients with breast cancer and the donors of the control group were obtained by performing oral swabs with the use of swabs. DNA extraction was performed by following the instructions of the commercial kit llustra TM blood GenomicPrep Mini Spin Kit (GE Healthcare, UK).

To achieve the amplification of sequences of microsatellites, we used the polymerase chain reaction (PCR) the following genomic regions: BAT40, BAT26, FMR2, Tp53, PCR15.1 and APC25. For all samples, the PCR products were denatured at $94^{\circ} \mathrm{C}$ in a solution of formamide and subjected to electrophoresis using the equipment Genephor (Pharmacia Biotech AB, Uppsala, Sweden) gels in Gene Gel Excel 15/24 (Amersham Pharmacia Biotech, Inc, USA) previously prepared for 1 hour at $600 \mathrm{~V}$ and $12^{\circ} \mathrm{C}$. After electrophoresis the gel was subjected to silver nitrate staining performed according to protocol instructions Silver Staining DNA Kit (Pharmacia Biotech) using the device Hoefer Gel Stainer Automed (Pharmacia Biotech, Uppsala, Sweden). The analysis of the gels was determined by visual inspection of silver staining by the investigators (PGCR and FLAF) for verification of the occurrence of genomic instability, this was considered LOH when there was a band and disappearance of MSI when there was an appearance of a band "attached" ${ }^{[2]}$.

\section{Statistical analysis}

Correlations between categorical variables were analysed using the $\chi^{2}$ or Fisher's exact test. Statistical calculations were performed using GraphPad Prism version 5.0 (GraphPad Software, San Diego, CA, USA).

\section{Results}

We evaluated 31 patients with mean age of 52.7 years (range 36-78) to the prevailing diagnosis of infiltrating ductal carcinoma and 10 women volunteers free of the disease which constituted the control group. The average age of the control Published by Sciedu Press 
group was 23.8 years (range 18-30 years). Women in the control group did not show genomic instability in oral mucosal cells.

The characteristics of patients regarding treatment, chemotherapy regimen used and presence of genomic instability are presented in the following table:

Table 1. Characteristics of patients related to the type of treatment, chemotherapy regimen used and presence of genomic instability.

\begin{tabular}{llll}
\hline Type & \% & Number of patients by type of & \% Instability \\
\hline Treatment & Patients & chemotherapy regime received & Genomics \\
Adjuvant & 45,16 & $05 \mathrm{AC} / 01 \mathrm{FEC} /$ 03 FAC / 01 TAC / 4 AC-T & 71,42 \\
Neoadjuvant & 45,16 & $02 \mathrm{AC} / 03 \mathrm{HT} /$ 01 FAC / 01 TAC/ 07 AC-T & 85,71 \\
Palliative & 9,67 & $02 \mathrm{AC} / 01 \mathrm{AC}-\mathrm{T}$ & 66,66 \\
\hline
\end{tabular}

Note: $\mathrm{A}=$ adriamycin; $\mathrm{C}=$ cyclophosphamide; $\mathrm{F}=5$-fluorouracil; $\mathrm{E}=$ epirubicin at a dose of $100 \mathrm{mg} / \mathrm{m} 2 ; \mathrm{T}=$ docetaxel; HT = hormone therapy; genomic instability due to events of this MSI and / or LOH.

We verified that $77.41 \%$ of patients showed any genetic alteration in the oral mucosal cells, with a higher number MSI events by $32.58 \%$ compared to LOH events by $24.97 \%$, mainly in the FMR2 (16.29\%) and BAT 26 (13.04\%). The region with the lowest expression was APC with (6.51\%) (Figure 1). Among the 17 patients who provided information on smoking, $35.29 \%$ were smokers, smoking in our study did not correlate with the presence of MSI $(P=0.102)$.

There was no correlation between changes in MSI in the studied areas between the oral mucosal cells and biological matrices such as mononuclear peripheral blood DNA from urine sediment and plasma DNA of women with breast cancer (Figure 1) previously studied by Pinto et al. ${ }^{[9]}$.

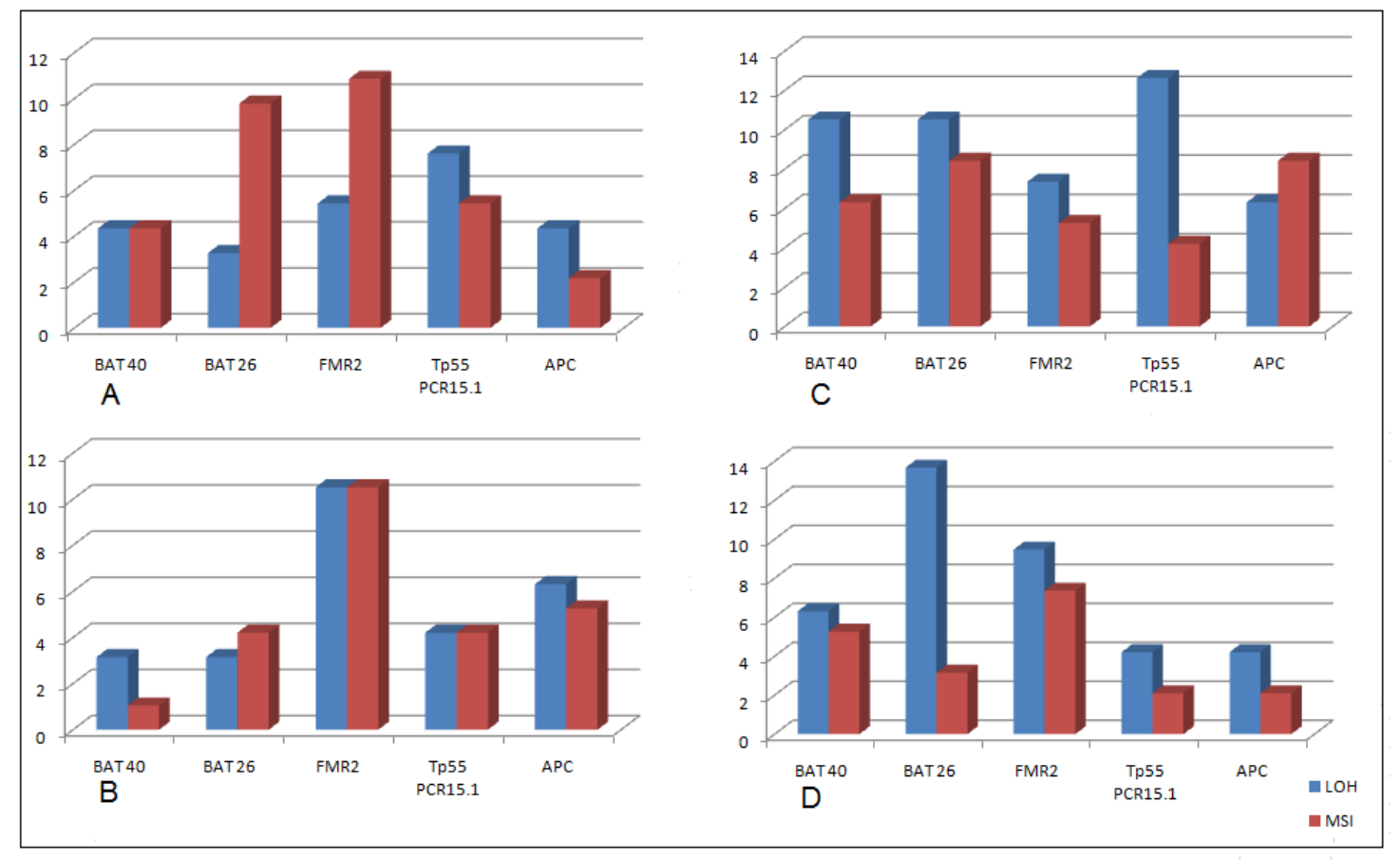

Figure 1. Percentage of events of genomic instability in the markers in samples of oral mucosal cells (A) compared to DNA from urine sediment (B), peripheral blood mononuclear fraction (C) and plasma DNA (D) studied by Pinto et al. ${ }^{[9]}$ 


\section{Discussion}

In our study we verified that oral mucosal cells are susceptible to genomic instability when exposed to chemotherapy regimens containing alkylating agents, assuming that the formation mechanism of instabilities occurring in different tissues not involved in the carcinogenesis.

The accumulation of these abnormalities, such as insertions and deletions may affect critical genes involved in controlling proliferation, differentiation and cell survival and thus direct the process of multiple steps in the development and progression of cancer ${ }^{[13]}$. The action of alkylating agents has as main target the cell cycle, justifying its therapeutic applications although their mutagenic and carcinogenic properties have been described repeatedly as a potential marker of susceptibility to cancer in humans ${ }^{[14]}$.

Fonseca et al. showed these effects of alkylating agents in the peripheral blood by inducing MSI and reduction of the gene expression of repair proteins such as $\mathrm{hMSH} 2$ and related the use of this drug with the emergence of secondary malignancies where was highlight the acute Leukemias and Myelodysplastic Syndrome ${ }^{[2]}$. In vitro model, exposure of lymphocytes exposed to alkylating agents was also observed to commitment DNA repair in cells that have no direct involvement in breast carcinogenesis simultaneously the generation of genomic instability ${ }^{[10]}$.

The secondary leukemias show frequently microsatellite instability and chromosomal aberrations that proves to be an indicator of genotoxicity in the long run, given that these leukemias arise in the period from 50 to 10 years after the end of treatment ${ }^{[9]}$. These secondary leukemias are usually preceded by myelodysplastic syndromes and are characterized by significant chemoresistance to treatment which represents a worse prognosis ${ }^{[2,9]}$. Although work on the genomic instability in tumor cells is constant in papers upon the induction of genomic instability in different biological matrices are scarce in literature ${ }^{[2]}$.

Among these works, Dietmaier et al. showed frequent MSI in both tumor cells from patients with HNPCC and sporadic as in non-neoplastic cells of the colonic mucosa of these patients, indicating that MSI can also occur in normal cells and should be considered in the analysis for MSI screening of the molecular HNPCC ${ }^{[8]}$. In a study of urinary sediment and plasma DNA of women with breast cancer Pinto et al. demonstrated the susceptibility of these biological matrices to genomic instability after exposure to alkylating agents ${ }^{[9]}$.

When comparing the different biological matrices such as oral mucosal cells, PBMNF, fpDNA fuDNA didn't show significant correlation in the regions studied perhaps by differential exposure of each biological matrix to systemic treatment, showing different susceptibilities in the genotoxicity of each cell type indicating different mechanisms for microsatellite instability found ${ }^{[15-18]}$. Recently, a study conducted on patients after allogeneic hematopoietic cells transplantation also demonstrated the occurrence of microsatellite instability in oral mucosa after transplantation. These results also show that it is possible to use the cells of the oral mucosa for evaluation of genomic instability ${ }^{[19]}$.

The genotoxicity found in this study, assessed by microsatellite instability in the regions of oral mucosal cells of women with breast cancer, allows a new approach to chemotherapy regimens and their implications besides proposing a new biological matrix for assessing such adverse effects ${ }^{[10,16]}$. In this context, the use of cytoprotective drugs to protect normal cells from genotoxicity action exercised by cancer chemotherapy, it is necessary besides permit the monitoring and increase doses of chemotherapy administered to patients without compromising anti-tumor action of chemotherapeutic used together, thus improving the survival and quality of life of patients and may reduce the genotoxic effects shown in various tissues ${ }^{[20]}$.

\section{Acknowledgement}

Financial support was provided by Fundação de Amparo à Pesquisa do Estado de São Paulo (FAPESP) (Grant 2005/00651-5) and NEPAS. 


\section{Conflict of interest}

The Author(s) declare(s) that they have no conflicts of interest to disclose.

\section{References}

[1] Bernard-Marty $\mathrm{C}$ et al. Second malignancies following adjuvant chemotherapy: 6 - year results from a Belgian randomized study comparing cyclophosphamide, methotrexate and 5 - fluorouracil (CMF) with an anthracycline-based regimen in adjuvant treatment of node-positive breast cancer patients. Ann. Oncol. 2003;14:693-98. PMid: $12702521 \mathrm{http} / / / \mathrm{dx}$. doi.org/10.1093/annonc/mdg204

[2] Fonseca FL et al. Systemic chemotherapy induces microsatellite instability in the peripheral blood mononuclear cells of breast cancer patients. Breast Cancer Res 2005;7:R28-R32. PMid:15642167 http://dx.doi.org/10.1186/bcr950

[3] Blasiak J et al. Basal, oxidative and alkylative DNA damage, DNA repair efficacy and mutagen sensitivity in breast cancer. Mutat. Res 2004;554:139-48. PMid:15450412 http://dx.doi.org/10.1016/j.mrfmmm.2004.04.001

[4] Boland CR et al. A National Cancer Institute Workshop on Microsatellite Instability for cancer detection and familial predisposition: Development of international criteria for the determination of microsatellite instability in colorectal cancer. Cancer Res 1998;58:5248-57. PMid:9823339

[5] Wooster R et al. Instability of short tandem repeats (microsatellites) in human cancers. Nat Genet 1994;6:152-56. PMid:8162069 http://dx.doi.org/10.1038/ng0294-152

[6] Thiagalingam $\mathrm{S}$ et al. Loss of heterozygosity as a predictor to map tumor suppressor genes in cancer: Molecular basis of its occurrence. Curr Opin Oncol 2002;14:65-72. PMid:11790983 http://dx.doi.org/10.1097/00001622-200201000-00012

[7] Richards RI, Sutherland GR. Heritable unstable DNA sequences. Nat Genet 1992;1:7-9. PMid:1302002 http://dx.doi.org/10.1038/ng0492-7

[8] Dietmaier W et al. Microsatellite instability in tumor and nonneoplastic colorectal cells from hereditary non-polyposis colorectal cancer and sporadic high microsatellite-instable tumor patients. Pathobiology 2000;68:227-31. PMid:11279351 http://dx.doi.org/10.1159/000055928

[9] Pinto J. L. F. et al. Systemic chemotherapy-induced microsatellite instability in the mononuclear cell fraction of women with breast cancer can be reproduced in vitro and abrogated by amifostine. J Pharm and Pharmacol 2010; 62:931-34. PMid:20636882

[10] Marsicano SR et al. Developing of in vitro model to asses genomic instability due alkylating agents in cell lines (MCF-7 and lymphocytes). In: XXXVII Annual Meeting of SBBq and IX Congress of the PABMB, 2008, Águas de Lindóia. SBBq-Program of the XXXVII Annual Meeting-2008. São Paulo: SBBq, 2008.(1):p110

[11] Lench, N et al. Simple non-invasive method to obtain DNA for gene analysis. Lancet 1988;331:1356-58. http://dx.doi.org/10.1016/S0140-6736(88)92178-2

[12] Garcia-Closas $M$ et al. Collection of genomicDNA from adults in epidemiological studies by buccal cytobrush and mouthwash. Cancer Epidemiol Biomarkers Prev 2001;10:687-96. PMid:11401920

[13] Goodison S et al. Molecular cytogenetic analysis of a human breast metastasis model: Identification of phenotype-specific chromosomal rearrangements. Cancer Genet Cytogenet 2005;156:37-48. PMid:15588854 http://dx.doi.org/10.1016/j.cancergencyto.2004.04.005

[14] Trenz K et al. Enhanced sensitivity of peripheral blood lymphocytes from women carrying a BRCA1 mutation towards the mutagenic effects of various cytostatics. Mutat Res 2003;544:279-88. http://dx.doi.org/10.1016/j.mrrev.2003.06.011

[15] Ehrlich M. DNA methylation in cancer: Too much, but also too little. Oncogene 2002:21:5400-13. PMid:12154403 http://dx.doi.org/10.1038/sj.onc. 1205651

[16] Leone et al. DNA methylation and demethylating drugs in myelodysplastic syndromes and secondary leukemias. Haematologica 2002;87:1324-41. PMid:12495905

[17] Ionov $\mathrm{Y}$ et al. Ubiqutous somatic mutations in simple repeated sequences reveal a new mechanism for colonic carcinogenesis. Nature 1993;363:558-61. PMid:8505985 http://dx.doi.org/10.1038/363558a0

[18] Umetani N et al. Prediction of Breast Tumor Progression by Integrity of Free Circulating DNA in Serum. J Clin Oncol 2006;24:4270-76. PMid:16963729 http://dx.doi.org/10.1200/JCO.2006.05.9493

[19] Khan FM et al. Genomic instability after allogeneic hematopoietic cell transplantation is frequent in oral mucosa, particularly in patients with a history of chronic graft-versus-host disease, and rare in nasal mucosa. Blood 2010;116:1803-06. PMid:20548092 http://dx.doi.org/10.1182/blood-2009-10-249201

[20] Cármino A et al. Cytoprotective therapy in patients treated with chemotherapy and/or antineoplasic radiotherapy.

Rev.bras.hematol.hemoter 2000;22:123-28. 